Opinion

\title{
What i've learned about medical education
}

\section{Opinion}

Teaching is my PASSION. I have been a Gastroenterology educator for over 34 years and have had the privilege of teaching audiences including medical students, housestaff, GI fellows, PA's, APRN's, and practicing clinicians.

\section{Here is what i have learned}

\section{Keep the message simple}

I always strive to focus on just a few important take-home points per lecture. I never include busy slides.

\section{Keep it practical}

Being a clinician, I have been confronted by patients whose diagnosis remains elusive. I use these cases in a very directed format to work through differential diagnoses with the audience. This gives them an insight into my thought process. It always opens up the presentation to discussions and occasional disagreements. I enjoy the disagreements. This furthers the interactivity. It also allows me to modify my slide deck for future use.

\section{Enthusiasm}

I start my lecture with humor if appropriate. I then shift into high energy levels modulating my voice. (Remember the movie "Good Morning Vietnam" where Robin Williams introduced his radio show?) The format is always open enough to allow for questions and disagreements. Tone and energy can make or break the learning environment.

\section{Your audience}

Each audience has its own personality. This is reflective in participation and enthusiasm. Certainly the ambient temperature of the room and the timing of the lecture (especially after lunch) has a tremendous influence on success.

We as educators need to know who are audience is in advance. Often times, before the lecture, I introduce myself to several audience members and ask them what they are looking to learn. This individual contact often leads to very meaningful discussions during my presentation.

It is essential to adjust the talk on the fly. When we see the audience "drifting", we need to immediately remediate. Humor, a small stretch break or questions are often helpful. Also, multiple choice questions used with either group hand raising or an audience participatory app is a wonderful way of making sure your teaching points are being understood.

\section{Know your topic and be current}

That means in this Google age knowing the breaking literature as it is occurring. I can assure you that someone in the audience is using

\author{
Volume 2 Issue 5 - 2015
}

\section{Peter S Buch}

Associate Clinical Professor, University of Connecticut Health Center, USA

Correspondence: Peter Buch, Associate clinical professor, University of Connecticut Health Center, Gastroenterology and Hepatology, 263 Farmington Avenue Farmington, CT 060308074, USA, Email ctgimd@aol.com

Received: August 23, 2015 | Published: September 8, 2015

their device to fact check! Don't be afraid to say "I don't know". This has occurred to me. I take the audience member's e mail and do my research and always get back to them. Incorporating some of these questions into my talks has made me a better lecturer.

\section{Weave your experiences into the presentation}

This should include successes and failures. I often elaborate my clinical mistakes to the audience. This shows my humanity and makes me much more approachable.

\section{Take questions as they occur}

This is why I love live discussions. But I would also say reading body language is equally important. When there are questions, I often ask follow up questions to make sure the topic is truly understood.

\section{Feedback}

Take note of your audience and peer feedback. Enjoy the positive feedback. Realize that negative feedback could be due to a host of issues, none of which may be related to you as a speaker. Should there be negative feedback, think about how the topic discussed meshed with the audience. Rework the concept. Perhaps other modalities like rounds, small group discussions or simulation would be a better choice in the future.

\section{Enjoy what you are doing}

This is the fuel you need to succeed.

\section{Acknowledgements}

None.

\section{Conflicts of interest}

The author declares that there is no conflict of interest. 